\title{
Hyperforin Suppresses Tumor Growth and NF-kB-mediated Anti-apoptotic and Invasive Potential of Non-small Cell Lung Cancer
}

\author{
WEI-TING CHEN ${ }^{1,2}$, YING-KAI CHEN ${ }^{3 *}$, SONG-SHEI LIN ${ }^{1 *}$ and FEI-TING HSU ${ }^{4-6 *}$ \\ ${ }^{1}$ Department of Medical Imaging and Radiological Sciences, \\ Central-Taiwan University of Science and Technology, Taichung, Taiwan, R.O.C.; \\ ${ }^{2}$ Department of Psychiatry, Zuoying Branch of Kaohsiung Armed \\ Forces General Hospital, Kaohsiung, Taiwan, R.O.C.; \\ ${ }^{3}$ Department of Internal Medicine, Zuoying Branch of Kaohsiung Armed \\ Forces General Hospital, Kaohsiung, Taiwan, R.O.C.; \\ ${ }^{4}$ Department of Radiology, School of Medicine, College of Medicine, \\ Taipei Medical University, Taipei, Taiwan, R.O.C., \\ ${ }^{5}$ Department of Medical Imaging, Taipei Medical University Hospital, Taipei, Taiwan, R.O.C.; \\ ${ }^{6}$ Research Center of Translational Imaging, College of Medicine, \\ Taipei Medical University, Taipei, Taiwan, R.O.C.
}

\begin{abstract}
Background/Aim: Previous studies have indicated that hyperforin inhibits tumor growth of hepatocellular carcinoma. However, the anticancer effects of hyperforin in non-small cell lung cancer (NSCLC) are ambiguous. The aim of the present study was to investigate the anticancer effect of hyperforin in NSCLC. NSCLC CL1-5-F4 cells were treated with different concentrations of hyperforin or $N F-k B$ inhibitor (QNZ) for different time periods. Materials and Methods: Change of cell viability, NF-kB activation, apoptotic signaling pathways, expression of anti-apoptotic proteins, and cell invasion were detected using the 3-(4,5Dimethylthiazol-2-yl)-2,5-diphenyltetrazolium bromide (MTT) assay, $N F-k B$ reporter gene assay, flow cytometry,
\end{abstract}

*These Authors contributed equally to this study.

Correspondence to: Ying-Kai Chen, Department of Internal Medicine, Zuoying Branch of Kaohsiung Armed Forces General Hospital, Kaohsiung, Taiwan, R.O.C. Tel: +886 75875938, e-mail: ccyykk0528@yahoo.com.tw; Song-Shei Lin, Department of Medical Imaging and Radiological Sciences, Central-Taiwan University of Science and Technology, Taichung, Taiwan, R.O.C. Tel: +886 422391647 \#7111, e-mail: sslin@ctust.edu.tw; Fei-Ting Hsu, Department of Radiology, Taipei Medical University, No. 252 Wu Hsing Street, Taipei, Taiwan 110, R.O.C. Tel: +886 227372181 \#1133, e-mail: sakiro920@gmail.com

Key Words: Hyperforin, NF-kB, non-small cell lung cancer, apoptosis, invasion. western blotting, and cell invasion assay. Results: The results demonstrated that hyperforin significantly promotes extrinsic and intrinsic apoptotic pathways, and inhibits cell viability and $N F-k B$ activation. In addition, results also indicated that blockage of NF-KB activation reduces the levels of antiapoptotic proteins and cell invasion in CL1-5-F4 cells. Conclusion: These results suggested hyperforin induces apoptosis and inhibits $N F-\kappa B$-modulated anti-apoptotic and invasive potential in NSCLC.

Globally, lung cancer is the leading cause of cancer-related death, and non-small cell lung cancer (NSCLC) is the most common type of lung cancer which occupies $85 \%(1,2)$. Approximately $70 \%$ of lung cancer patients have locally advanced or metastatic disease at the time of diagnosis (3). Even after common treatment strategy such as curative resection, chemotherapy and radiotherapy, 5-year overall survival remains relative poor (4). Therefore, development of potential anticancer agents is critical for patients with NSCLC.

Tumor progression was activated by multiple intracellular signaling pathways. Currently, treatment target of NSCLC is focused on specific molecules which modulate tumor progression (5). Nuclear factor-kappaB (NF-kB), the transcriptional factor that regulates expression of a number of oncogenes, plays an essential role in NSCLC progression (6). Active NF-kB induces expression of anti-apoptotic proteins, such as X-linked inhibitor of apoptosis protein (XIAP), myeloid leukemia cell differentiation protein 1 (MCL-1) and Cellular FLICE (FADD-like IL-1 $\beta$-converting enzyme)- 
inhibitory protein (c-FLIP) (7). Ferreira et al. suggested that XIAP expression is a prognostic marker in NSCLC (8). MCL-1 is also identified as a critical factor for NSCLC survival (9). Moreover, c-FLIP expression is an indicator of NSCLC with poor prognosis. In addition, sustained activation of $\mathrm{NF}-\mathrm{kB}$ has been associated with increasing NSCLC invasive ability (10). Among these, the alteration of NF-kBmediated anti-apoptotic mechanism and invasion capacity are the sticking point of NSCLC therapy design.

Hyperforin, a major lipophilic constituent extracted from plant Hyperforin perforatum L., has been used for centuries as a treatment of depression (11). Besides the antidepression, anti-inflammation, and antimicrobial effects, hyperforin was recently found to have anti-tumoral potential (12). Hyerforin may inhibit tumor growth by prompted expression of apoptotic proteins in breast cancer and hepatocellular carcinoma $(13,14)$. Hyperforin triggers proapoptotic activities and inhibits expression of anti-apoptotic proteins in leukemic cells from patients with B-cell chronic lymphocytic leukemia (15). In addition to apoptosis induction, hyperforin was also found to have an inhibitory effect on cancer invasive potential (16). However, whether hyperforin showed anti-tumor effect on NSCLC remains vague and the putative underlying mechanism may also need to be elucidated.

\section{Materials and Methods}

Chemical reagents and antibodies. Hyperforin and NF-kB inhibitor 4$\mathrm{N}$-[2-(4-phenoxyphenyl) ethyl] quinazoline-4, 6-diamine (QNZ) were purchased from Sigma-Aldrich (St. Louis, MO, USA) and Selleckchem (Houston, TX, USA), respectively, both of them are prepared as $1 \mathrm{mM}$ stock in Dimethyl sulfoxide (DMSO). Primary antibodies to MCL-1 and cellular FLICE (FADD-like IL-1 $\beta$ converting enzyme)-inhibitory protein (c-FLIP) were bought from BioVision (Milpitas, CA, USA) and Cell Signaling Technology (Beverly, MA, USA), respectively. Primary antibody to Caspase-8 and $\mathrm{X}$-linked inhibitor of apoptosis protein (XIAP) were obtained from Thermo Fisher Scientific (Fremont, CA, USA). Primary antibodies to $\beta$-actin and the antibiotic hygromycin B were bought from Santa Cruz Biotechnology (Santa Cruz, CA, USA). Secondary antibodies were purchased from Jackson ImmunoResearch (West Grove, PA, USA). D-luciferin was bought from Caliper (Hopkinton, MA, USA).

Cell culture. The highly metastatic human lung adenocarcinoma cell line, CL1-5-F4, was provided by Dr. Chia-Lin Hsieh (Taipei Medical University, Taiwan). Culture medium of CL1-5-F4 was Dulbecco's Modified Eagle's Medium (DMEM) and Ham's F-12 Nutrient Mixture and supplemented with $10 \%$ fetal bovine serum (FBS), $1 \% \mathrm{~L}-$ glutamine, penicillin, and streptomycin. (FBS), L-glutamine (2 mM), and penicillin $(100 \mathrm{U} / \mathrm{ml})$-streptomycin $(100 \mathrm{mg} / \mathrm{ml})$ were obtained from Gibco/Life Technologies (Carlsbad, CA, USA). Cells were incubated at $37^{\circ} \mathrm{Cin}$ an atmosphere of $5 \% \mathrm{CO}_{2}, 95 \%$ (17).

MTT assay. 3-(4, 5-Dimethylthiazol-2-yl)-2,5-diphenyltetrazolium bromide (MTT) was purchased from Sigma-Aldrich and prepared as $5 \mathrm{mg} / \mathrm{ml}$ stock in phosphate-buffered saline buffer. Cells were plated in 96-well $\left(2 \times 10^{4} /\right.$ well $)$ for $24 \mathrm{hr}$ and treated with various dose of hyperforin or QNZ for $48 \mathrm{hr}$. After treatment, medium was replaced with MTT solution (1:9=MTT stock: medium) and maintained in the incubator for another four hours. Before ELISA (Tecan Group Ltd., Männedorf, Switzerland) reader analysis, MTT solution was replaced by $100 \mu \mathrm{DMSO}$. Absorbance wavelength of MTT is $570 \mathrm{~nm}$ and reference wavelength is $650 \mathrm{~nm}$, blank value was defined as zero $(+/-0.1)$.

Establishment of CL1-5-F4 NF- $\mathrm{kB}$ reporter gene stable clone. $1 \times 10^{6}$ CL1-5-F4 cells were plated in $6 \mathrm{~cm}$ dish to growth for $24 \mathrm{hr}$ before transfection. JetPEI ${ }^{\mathrm{TM}}$ transfection agent and NF-kB-luciferrase2 vector ( $\mathrm{pNF}-\mathrm{kB} / l u c 2$ ) were obtained from Polyplus Transfection (Illkirch, Bas-Rhin, France) and Promega (Madison, WI, USA), respectively. The transfection protocol of $\mathrm{pNF}-\mathrm{kB} / l u c 2$ was described in detail in a previous study (18). CL1-5-F4 NF-kB reporter gene stable clones were selected by IVIS 200 Imaging System (Xenogen, Alameda, CA, USA) and named CL1-5-F4/NF-kB-luc2 cells.

$N F-k B$ reporter gene assay. CL1-5-F4/NF-kB-luc2 cells were plated into 96-well $\left(2 \times 10^{4} /\right.$ well $)$ for $24 \mathrm{~h}$ and treated with various concentrations of hyperforin or $0.5 \mu \mathrm{M}$ QNZ for $48 \mathrm{~h}$. After treatment, $100 \mu \mathrm{l}$ D-luciferin solution $(500 \mu \mathrm{M}$ D-luciferin in $100 \mu \mathrm{l}$ PBS) was added into each well before image acquisition, photon signal was collected for $1 \mathrm{~min}$ by IVIS 200 Imaging System. Cell viability was evaluated by using MTT assay and used to correct relative NF-KB activity $(19,20)$.

Cell cycle analysis. CL1-5-F4 cells were seeded into 12-well $\left(2 \times 10^{5} /\right.$ well $)$ for $24 \mathrm{~h}$ and treated with various concentrations of hyperforin for $48 \mathrm{~h}$. After hyperforin treatment, cells were harvested by centrifugation and fixed by $75 \%$ ethanol gently and stored at $-20^{\circ} \mathrm{C}$ overnight. Then, cells were centrifuged and labeled by $40 \mu \mathrm{g} / \mathrm{ml}$ Propidium iodide (PI) dye (contained with $100 \mu \mathrm{g} / \mathrm{ml}$ RNase and $1 \%$ Triton X-100) in phosphate-buffered saline buffer (PBS) for thirty minutes in the dark at $37^{\circ} \mathrm{C}$. Ultimately, the signal intensity of PI dye in CL1-5-F4 cells were validated by flow cytometry (FACS101, Becton Dickinson FACScan, Franklin Lakes, NJ, USA) (21).

Detection of mitochondria membrane potential (MMP). CL1-5-F4 cells were plated into 12 -well plates $\left(2 \times 10^{5} /\right.$ well) for $24 \mathrm{~h}$ and treated with various concentrations of hyperforin for $48 \mathrm{~h}$. After hyperforin treatment, cells were harvested by centrifugation and labeled with $4 \mu \mathrm{M} \mathrm{DiOC} 6$ in $500 \mu \mathrm{l} \mathrm{PBS}$ for $30 \mathrm{~min}$ at $37^{\circ} \mathrm{C}$. Detection of MMP was performed by using flow cytometry as described by Hsu et al. (18).

Caspase-3 and caspase- 8 activation analysis. CL1-5-F4 cells were plated into 12 -well plates $(2 \times 105 /$ well $)$ for $24 \mathrm{~h}$ and treated with various concentrations of hyperforin for $48 \mathrm{~h}$. Cells were harvested by centrifugation and labeled with caspase- 3 activation probe $(1 \mu \mathrm{l}$ FITC-DEVD-FMK in $300 \mu \mathrm{l}$ PBS) or caspase- 8 activation probe (1 $\mu 1$ Red-IETD-FMK in $300 \mu \mathrm{l} \mathrm{PBS}$ ) for $30 \mathrm{~min}$ in $37^{\circ} \mathrm{C}$ incubator, respectively. Labelled cells were harvested, washed and then sent to flow cytometry system. The effect of hyperforin on caspase- 3 and caspase- 8 activation were finally validated by flow cytometry on FL1 or FL-2 channel (21).

Western blotting assay. $2 \times 10^{6}$ CL1-5-F4 cells were plated into $10 \mathrm{~cm}$ dishes for $24 \mathrm{~h}$ and treated with various concentrations of hyperforin 

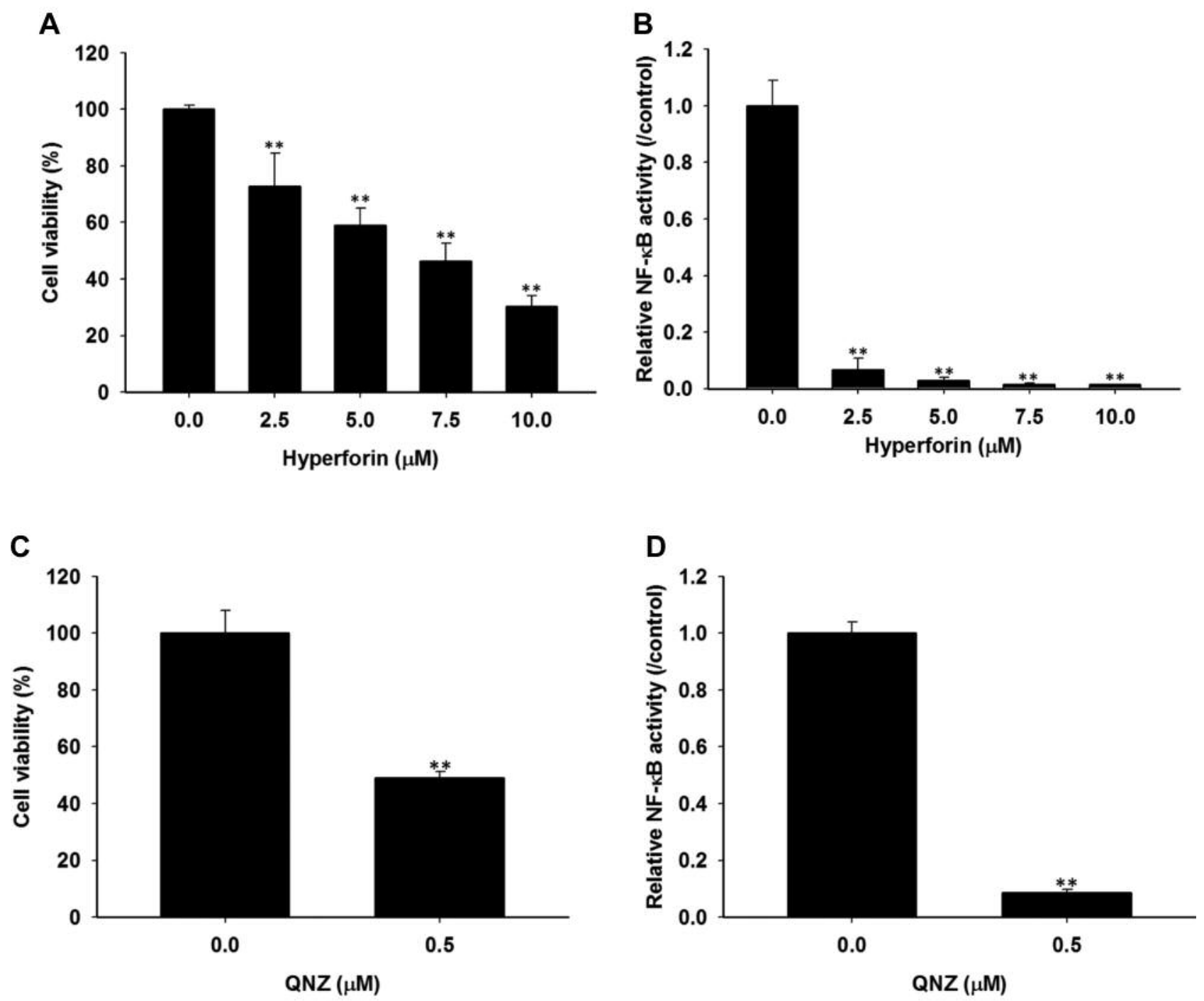

Figure 1. Hyperforin and NF-kB inhibitor (QNZ) reduce cell growth and NF-kB activation in CL1-5-F4 cells. CL1-5-F4 cells were treated with different concentrations $(0-10 \mu M)$ of hyperforin or $0.5 \mu M Q N Z$ for $48 \mathrm{~h}$. Cell viability and $N F-K B$ activation were detected with MTT and $N F-k B$ reporter gene assays. Effect of hyperforin on cell viability $(A)$ and $N F-k B$ activation $(B)$. Effect of $Q N Z$ on cell viability $(C)$ and $N F-k B$ activation (D). ${ }^{* *} p<0.01$ compared to control $(0.1 \%$ DMSO).

or $0.5 \mu \mathrm{M}$ QNZ for $48 \mathrm{~h}$. After treatment, protein was extracted from each group by lysis buffer $(50 \mathrm{mM}$ Tris- $\mathrm{HCl} \mathrm{pH} 8.0,120 \mathrm{mM} \mathrm{NaCl}$, $0.5 \%$ NP-40, and $1 \mathrm{mM}$ phenylmethanesulfonyl fluoride). Proteins were separated by $10-15 \%$ SDS-PAGE, and transferred to $0.2 \mu \mathrm{m}$ polyvinylidene difluoride membrane. Then PVDF membrane stained by primary and secondary antibodies. Lastly, proteins were identified by ECL reagents (Pierce, Rockford, IL, USA), and the protein was visualized using the ChemiDoc MP Imaging System (Bio-Rad Laboratories, Inc., CA, USA). The level of protein bands was measured by Bio-Rad Image Lab software (19).

Invasion assay. Matrigel and $8 \mathrm{~mm}$ pore transwells were purchased from Corning (Tewksbury, MA, USA). Matrigel was coated at upper channel of transwell one day before invasion experiment. CL1-5-F4 cells were treated with different concertations of hyperforin or $0.5 \mu \mathrm{M}$ QNZ for $48 \mathrm{~h}$ and then collected into upper channel of transwell at number of $1 \times 10^{6}$. Allow $24 \mathrm{~h}$ invasion effect of CL1-5-F4 cells, followed with fixation (methanol and acetic acid 3:1) and staining ( $0.5 \%$ crystal violet) step. The light microscope Nikon ECLIPSE Ti$\mathrm{U}$ was used to photograph the invaded cells at $\times 100$. The number of invaded cells was calculated using ImageJ software version 1.50 (National Institutes of Health, Bethesda, MD, USA) (21).

Statistical analysis. Student's $t$-test was performed in this study to compare the difference between control and hyperforin treatment groups. $p$-Value smaller than 0.05 was defined as significant difference. Each value in this study was displayed as mean \pm standard error. Details of each statistical analysis is recorded in the figure legends. 
A

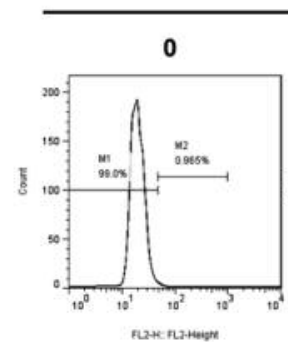

Hyperforin $(\mu \mathrm{M})$

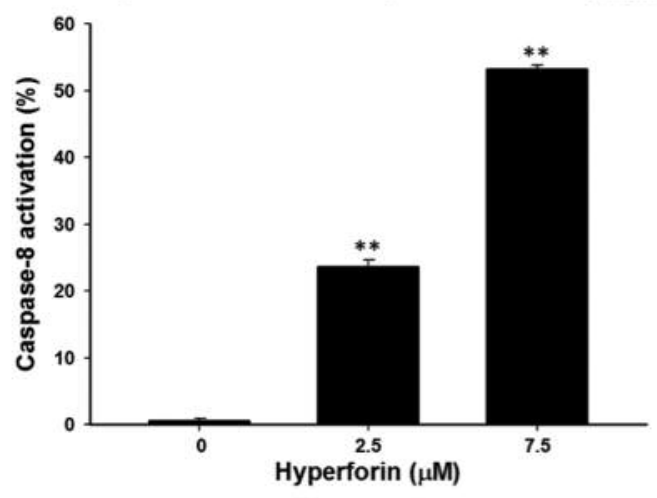

C

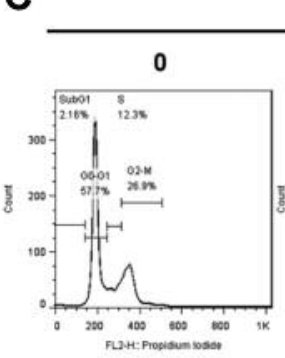

Hyperforin $(\mu \mathrm{M})$

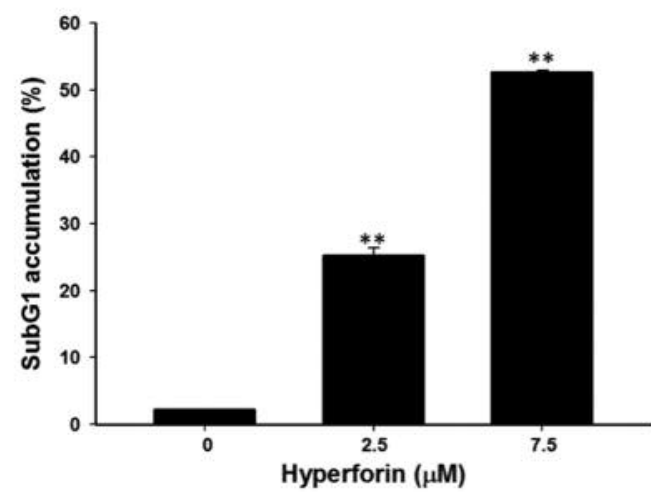

B
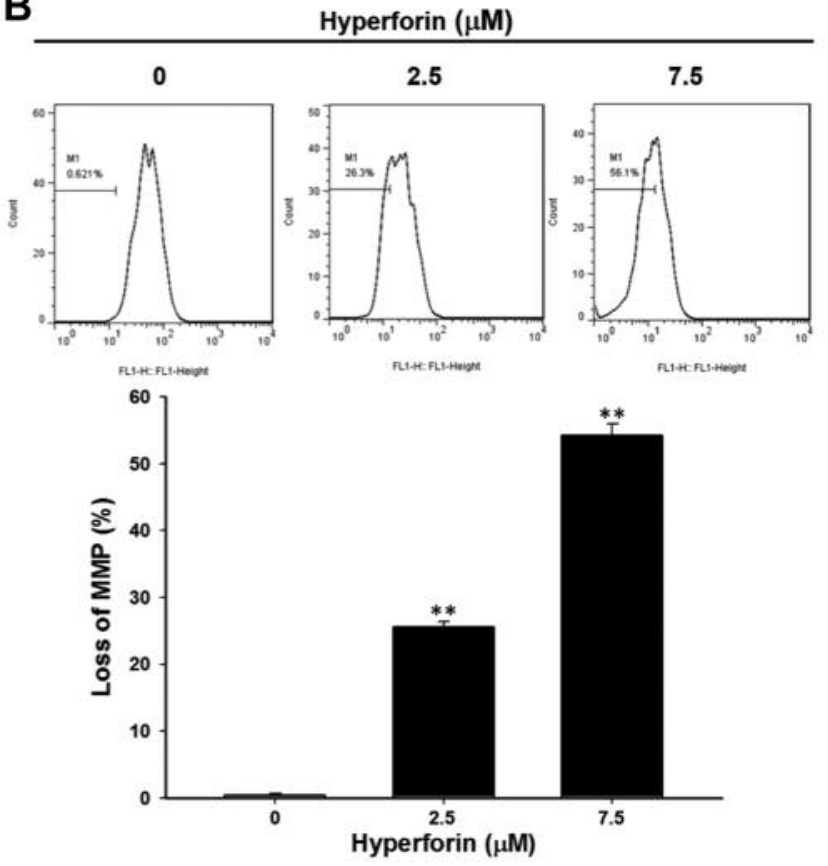

D

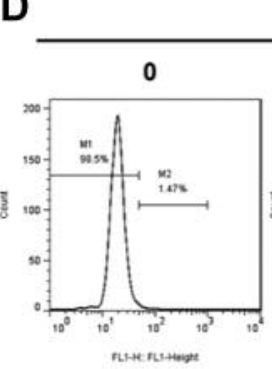

Hyperforin $(\mu \mathrm{M})$
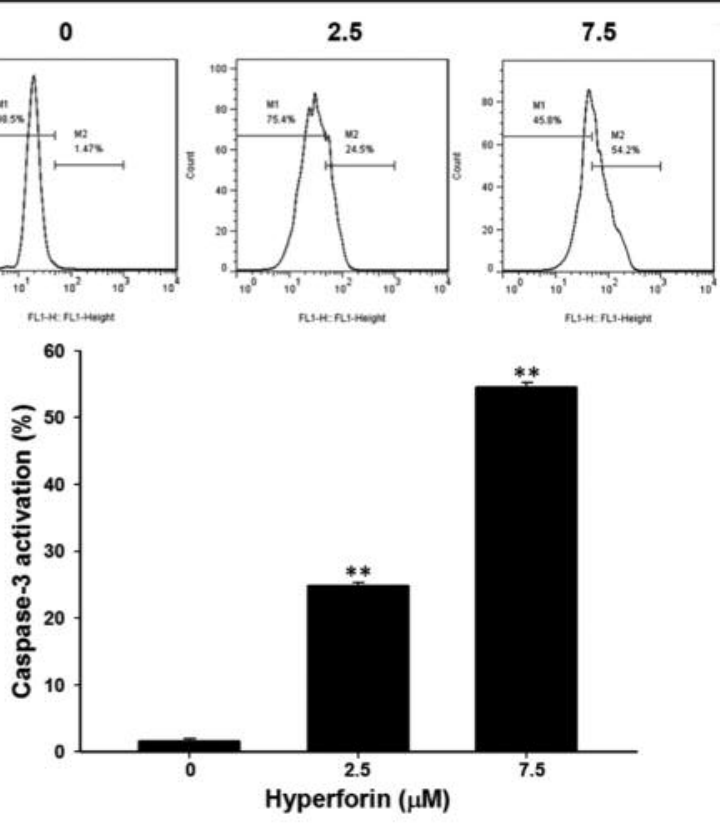

Figure 2. Hyperforin triggers extrinsic and intrinsic apoptosis. CL1-5-F4 cells were treated with different concentrations $(0,2.5$, and 7.5 $\mu M)$ of hyperforin for 48 h. Hyperforin-induced apoptotic signaling were analyzed using flow cytometry. (A) Detection of caspase-8 activation. (B) Detection of MMP. (C). Analysis of cell cycle. (D). Detection of caspase-3 activation. ${ }^{* *} p<0.01$ compared to control $(0.1 \%$ DMSO).

\section{Results}

Hyperforin effectively induces cytotoxicity via suppression of $N F-k B$ activation in CL1-5-F4 cells. MTT assay was used to examine the cytotoxicity of hyperforin in CL1-5-F4 cells. As showed in Figure 1A, hyperforin dose-dependently enhanced cytotoxicity of CL1-5-F4 cells. Through NF-kB reporter gene assay, we found that hyperforin also significantly 

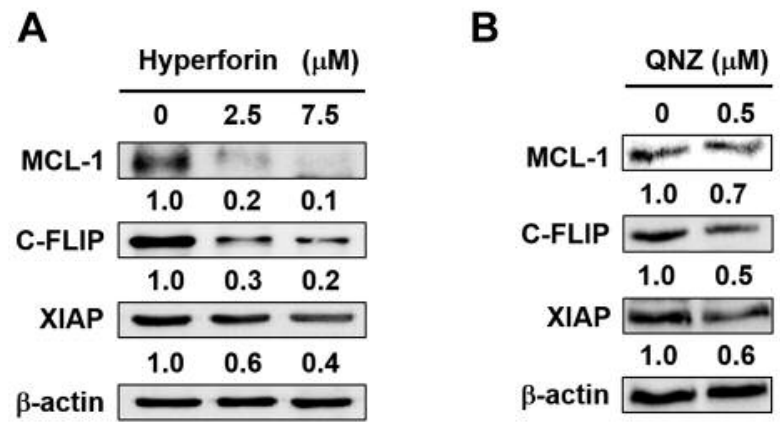

Figure 3. Both hyperforin and $Q N Z$ suppress expression of anti-apoptotic proteins in CL1-5-F4 cells. CL1-5-F4 cells were treated with different concentrations $(0,2.5,7.5 \mu \mathrm{M})$ of hyperforin or $0.5 \mu \mathrm{M} Q N Z$ for $48 \mathrm{~h}$. Levels of MCL-1,C-FLIP, and XIAP proteins were evaluated with Western blotting assay. (A) Hyperforin treatment. (B) QNZ treatment.

inhibited NF-kB activation in CL1-5-F4 cells (Figure 1B). NF-kB inhibitor, QNZ, was used to examine whether blockage of NF-KB activation inhibits cell growth in CL1-5F4 cells. Figure $1 \mathrm{C}-\mathrm{D}$ shows that QNZ significantly inhibits of tumor growth and NF-kB activation in CL1-5-F4 cells.

Hyperforin triggers apoptosis through induction of extrinsic and intrinsic pathways in CL1-5-F4 cells. After confirming the effect of hyperforin on cell growth and NF-kB activation, we evaluated mechanism of hyperforin-induced apoptosis in CL1-5-F4 cells by using flow cytometry. Caspase- 8 activation and loss of MMP are characteristic markers of extrinsic and intrinsic apoptotic pathways, respectively. We found that hyperforin significantly augments caspase- 8 activation and loss of MMP as compared to control group (Figure 2A-B). Accumulation of $\operatorname{subG}_{1}$ population and caspase-3 activation are related to apoptosis. Figure $2 \mathrm{C}-\mathrm{D}$ indicats that hyperforin significantly promotes accumulation of subG $\mathrm{S}_{1}$ population and caspase- 3 activation by $25-50 \%$ and $30-60 \%$ as compared to control group, respectively.

Hyperforin suppresses expression of $\mathrm{NF}-\mathrm{kB}$-modulated antiapoptotic proteins in CL1-5-F4 cells. Next, Western blotting assay was used to investigate whether hyperforin alters expression of NF-kB-modulated anti-apoptotic proteins in CL1-5-F4 cells. Protein levels of XIAP, MCL-1, and C-FLIP were diminished after hyperforin treatment (Figure 3A). QNZ also suppressed the expression of XIAP, MCL-1, and C-FLIP (Figure 3B). In sum, both hyperforin and QNZ reduced expression of anti-apoptotic proteins (MCL-1, CFLIP, and XIAP) by 30-90\% compared to control group.

Hyperforin markedly reduces $N F-k B$-modulated invasive ability of CL1-5-F4 cells. CL1-5-F4 cells are belonged to
NSCLC with high metastatic potential (17). We used invasion assay to investigate the effect of hyperforin and QNZ on the invasive ability of CL1-5-F4 cells. Here, our results indicated that hyperforin inhibited CL1-5-F4 cells invasion (Figure 4A). QNZ treatment also showed similar inhibition effect on CL1-5-F4 cells invasion (Figure 4B).

\section{Discussion}

Hyperforin has been suggested to have the potential to block the growth of liquid and solid tumor, including leukemia, hepatocellular carcinoma, and breast cancer $(11,13,14)$. In these cancer types, multiple apoptotic mechanisms were found to be markedly activated by hyperforin. In addition to the induction of apoptosis, hyperforin has also been suggested to exert anti-invasive and anti-metastatic properties during cancer treatment (16). Regarding NSCLC, the challenge for both clinicians and scientists is how to tailor treatment to achieve the best response and avoid unnecessary toxicities remains. There is no report to discuss the anti-tumor function of hyperforin on any type of lung cancer. In this study, we examined whether hyperforin may also serve as a novel agent for NSCLC therapy.

Although some studies suggested that hyperforin may be functioning on apoptosis pathways, the molecular mechanism of hyperforin on NSCLC has not been defined yet. At the molecular level, in lung cancer, NF-kB, in not only a leading mediator for lung carcinogenesis but also a target for prevention and therapy (6). Gehan H. et al. reported that expression of NF-kB/p65 has a prognostic value and impact on survival of NSCLC patients, and that it is also a suitable target for development of new lung cancer therapies (22). The NF-kB reporter gene assay applied in this study indicated that hyperforin significantly reduces NF-KB activation in CL1-5-F4 cells (Figure 1B). Furthermore, the NF-kB inhibitor (QNZ) confirmed the effect of hyperforin indicating that blockage of NF-KB activation is critical anti-growth factor in NSCLC (Figure 1C-D). In extrinsic apoptotic mechanisms, death signal is delivered from Fas-associated death domain to caspase-8, which activates downstream effector caspases (23). Increased caspase- 8 activation was found in hyperforin treated groups by flow cytometry (Figure 2A). NF-kB mediated anti-apoptotic proteinsc-FLIP which negatively alters caspase- 8 signaling, was also down-regulated by hyperforin (Figure 3A). In intrinsic apoptotic mechanisms, the potential loss of MMP mediates apoptosis (23). Our flow cytometry results indicated that hyperforin triggers the loss of MMP (Figure 2B). Furthermore, MCL-1-mediated impairment of the intrinsic apoptosis pathways was also diminished by hyperforin (Figure 3A). In Figure $2 \mathrm{C}$ and $2 \mathrm{D}$, apoptosis activation by hyperforin was also confirmed by increasing subG $\mathrm{G}_{1}$ population and caspase- 3 activation. We provide evidence that hyperforin eliminated the activation of NF-kB and NF-kB-mediated anti-apoptotic 
A Hyperforin $(\mu \mathrm{M})$

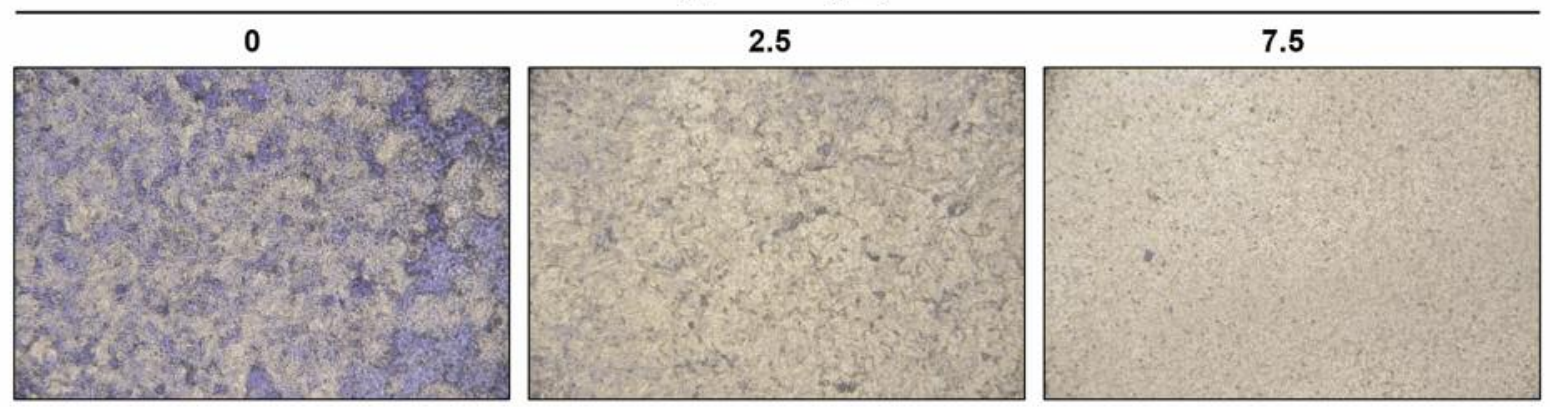

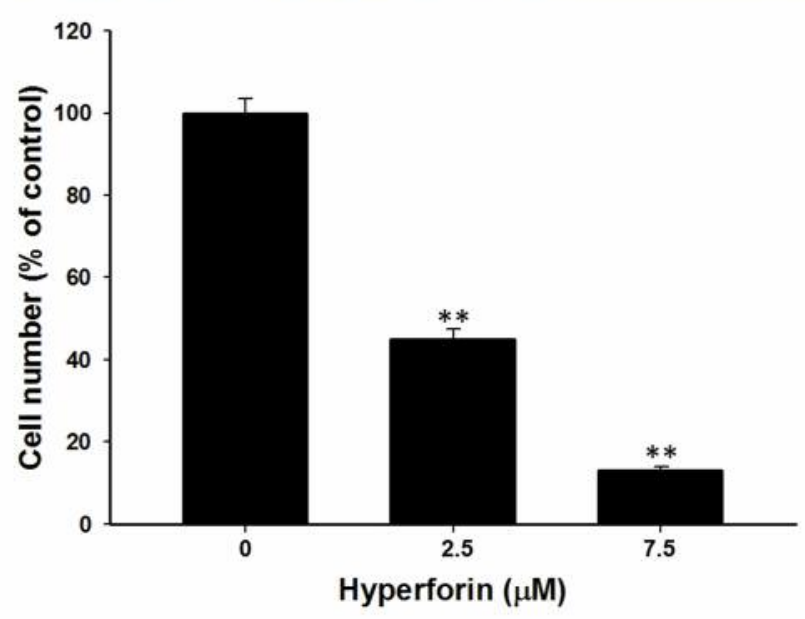

B
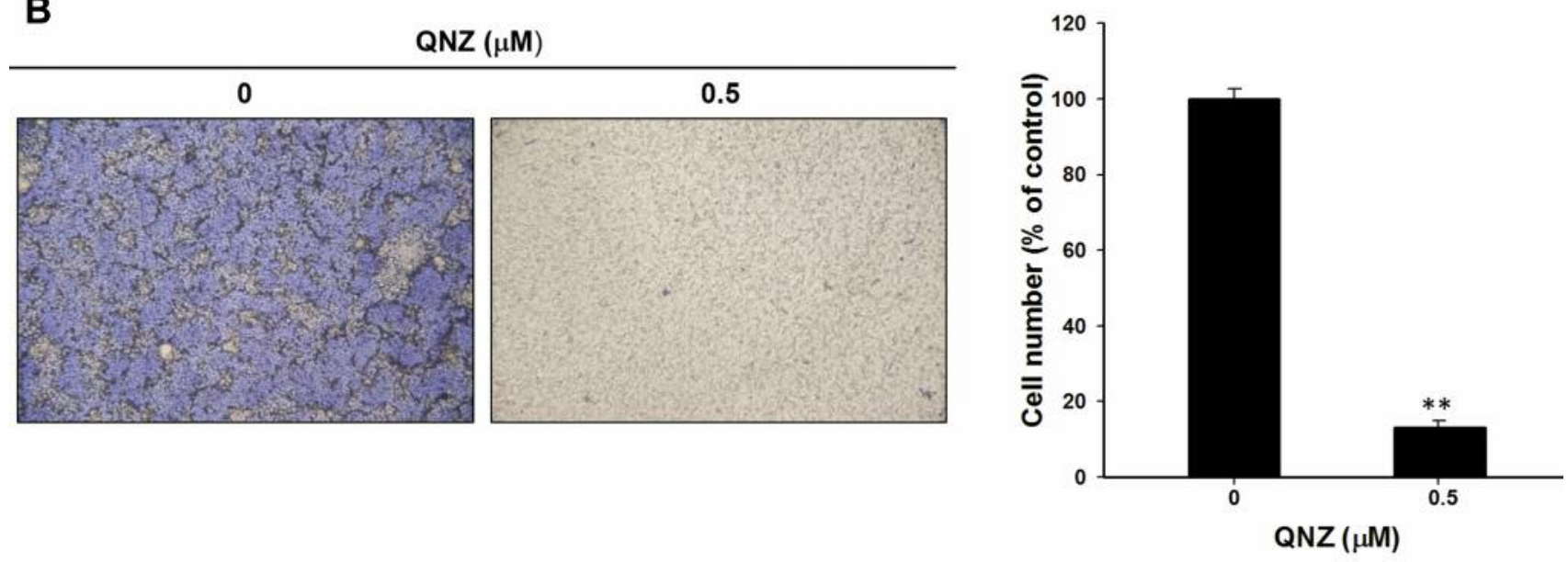

Figure 4. Both hyperforin and QNZ reduce cells invasion ability of CL1-5-F4 cells. CL1-5-F4 cells were treated with different concertations (0, 2.5, $7.5 \mu \mathrm{M})$ of hyperforin or $0.5 \mu \mathrm{M} Q \mathrm{QNZ}$ for $48 \mathrm{~h}$ and then harvested for invasion assay. Number of invaded cells was quantified by Image software. (A) Hyperforin treatment. (B) QNZ treatment. ${ }^{*} p<0.01$ compared to control $(0.1 \%$ DMSO).

proteins expression, as well as facilitated extrinsic and intrinsic apoptotic signaling transduction.

While one of the important characteristic of tumor progression is invasion capacity, previous study also suggested that NF-kB is an important modulator on this property (6). High capacity of invasion correlates with more aggressive behavior as well as much shorter overall survival in lung cancer patient (24). Therefore, reducing invasion ability may offer benefits in NSCLC therapeutic efficacy. Our (Figure 4B) results indicate that NF-kB inhibition may effectively decrease the number of invaded cells. Most importantly, hyperforin may also act as an invasion inhibitor of NSCLC through inhibition 
of NF-kB activation (Figure 4A). In conclusion, hyperforin is a novel agent for NSCLC treatment. Hyperforin can not only induces apoptosis in NSCLC, but also successfully decreases the invasive potential of NSCLC.

\section{Conflicts of Interest}

The Authors disclose no potential conflicts of interest.

\section{Acknowledgements}

The study was supported by Taipei Medical University and Taipei Medical University Hospital (grant no. grant no. TMU105-AE1-B49 and 105TMU-TMUH-23). This project was also supported by the National Health Research Institutes (MG-105-SP-07, MG-106-SP07). This study was also funded by Zuoying Branch of Kaohsiung Armed Forces General Hospital, Kaohsiung, Taiwan, R.O.C (grant no. ZBH106-17).

\section{References}

1 Molina JR, Yang P, Cassivi SD, Schild SE and Adjei AA: Nonsmall cell lung cancer: epidemiology, risk factors, treatment, and survivorship. Mayo Clinic proceedings 83(5): 584-594, 2008.

2 Zhou C: Lung cancer molecular epidemiology in China: recent trends. Transl Lung Cancer Res 3(5): 270-279, 2014.

3 Reck M, Heigener DF, Mok T, Soria JC and Rabe KF: Management of non-small-cell lung cancer: recent developments. Lancet (London, England) 382(9893): 709-719, 2013.

4 Ridge CA, McErlean AM and Ginsberg MS: Epidemiology of Lung Cancer. Seminars in Interventional Radiology 30(2): 93 98, 2013.

5 National Cancer Institute SEER Cancer Statistics Review 19752008. Lifetime Risk (Percent) of Being Diagnosed with Cancer by Site and Race/Ethnicity: Mppales, 17 SEER Areas, 20062008 (Table 1.15) and Females, 17 SEER Areas, 2006-2008 (Table 1.16). Available at: http://seer.cancer.gov/csr/1975_2008/ results_merged/topic_lifetime_risk_diagnosis.pdf. Accessed October 15, 2012.

6 Chen W, Li Z, Bai L and Lin Y: NF-kappaB in lung cancer, a carcinogenesis mediator and a prevention and therapy target. Front Biosci (Landmark ed) 16: 1172-1185, 2011.

7 Karin M and Lin A: NF-kappaB at the crossroads of life and death. Nature Immunol 3(3): 221-227, 2002.

8 Ferreira CG, van der Valk P, Span SW, Ludwig I, Smit EF, Kruyt FA, Pinedo HM, Tinteren H and Giaccone G: Expression of Xlinked inhibitor of apoptosis as a novel prognostic marker in radically resected non-small cell lung cancer patients. Clin Cancer Res 7(8): 2468-2474, 2001.

9 Zhang H, Guttikonda S, Roberts L, Uziel T, Semizarov D, Elmore SW, Leverson JD and Lam LT:. Mcl-1 is critical for survival in a subgroup of non-small-cell lung cancer cell lines. Oncogene 30(16): 1963-1968, 2011.

10 Cai Z, Tchou-Wong K-M and Rom WN: NF-kappaB in Lung Tumorigenesis. Cancers 3(4): 4258-4268, 2011.

11 Quiney C, Billard C, Salanoubat C, Fourneron JD and Kolb JP: Hyperforin, a new lead compound against the progression of cancer and leukemia? Leukemia 20: 1519, 2006.
12 Hostanska K, Bommer S, Weber M, Krasniqi B and Saller R: Comparison of the growth-inhibitory effect of Hypericum perforatum L. extracts, differing in the concentration of phloroglucinols and flavonoids, on leukaemia cells. J Pharm Pharmacol 55(7): 973-980, 2003.

13 Schempp CM, Kirkin V, Simon-Haarhaus B, Kersten A, Kiss J, Termeer CC, Gilb B, Kaufmann T, Borner C, Sleeman JP and Simon JC: Inhibition of tumour cell growth by hyperforin, a novel anticancer drug from St. John's wort that acts by induction of apoptosis. Oncogene 21(8): 1242-1250, 2002.

14 Chiang IT, Chen WT, Tseng CW, Chen YC, Kuo YC, Chen BJ,Weng MC, Lin HJ and Wang WS: Hyperforin inhibits cell growth by inducing intrinsic and extrinsic apoptotic pathways in hepatocellular carcinoma cells. Anticancer Res 37(1): 161-167, 2017.

15 Quiney C, Billard C, Faussat AM, Salanoubat C, Ensaf A, NaitSi Y, Fourneron JD and Kolb JP: Pro-apoptotic properties of hyperforin in leukemic cells from patients with B-cell chronic lymphocytic leukemia. Leukemia 20(3): 491-497, 2006.

16 Dona M, Dell'Aica I, Pezzato E, Sartor L, Calabrese F, Della Barbera M, Donella-Deana A, Appendino G, Borsarini A, Caniato $\mathrm{R}$ and Garbisa S: Hyperforin inhibits cancer invasion and metastasis. Cancer Res 64(17): 6225-6232, 2004.

17 Ali AA, Hsu FT, Hsieh CL, Shiau CY, Chiang CH, Wei ZH, Chen CY and Huang HS: Erlotinib-Conjugated Iron Oxide Nanoparticles as a Smart Cancer-Targeted Theranostic Probe for MRI. Sci Rep 6: 36650, 2016.

18 Tsai JJ, Pan PJ and Hsu FT: Regorafenib induces extrinsic and intrinsic apoptosis through inhibition of ERK/NF-kappaB activation in hepatocellular carcinoma cells. Oncol Rep 37(2): 1036-1044, 2017.

19 Chiang IT, Liu YC, Wang WH, Hsu FT, Chen HW, Lin WJ, Chang WY and Hwang JJ:. Sorafenib inhibits TPA-induced MMP-9 and VEGF expression via suppression of ERK/NFkappaB pathway in hepatocellular carcinoma cells. In Vivo 26(4): 671-681, 2012.

20 Chen JC, Chuang HY, Hsu FT, Chen YC, Chien YC and Hwang $\mathrm{JJ}$ : Sorafenib pretreatment enhances radiotherapy through targeting MEK/ERK/NF-kappaB pathway in human hepatocellular carcinoma-bearing mouse model. Oncotarget 7(51): 85450-85463, 2016.

21 Hsu FT, Sun CC, Wu CH, Lee YJ, Chiang CH and Wang WS: regorafenib induces apoptosis and inhibits metastatic potential of human bladder carcinoma cells. Anticancer Res 37(9): 49194926, 2017.

22 Abo El-Magd GH, Abd El-Fattah O and Saied EM: Immunohistochemical expression of nuclear factor kappa-B/p65 and cyclooxygenase-2 in non-small cell lung cancer patients: Prognostic value and impact on survival. Egypt $\mathbf{J}$ Chest Dis Tuberc 63(1): 193-200, 2014.

23 Fulda S and Debatin KM: Extrinsic versus intrinsic apoptosis pathways in anticancer chemotherapy. Oncogene 25: 4798, 2006.

24 Popper HH: Progression and metastasis of lung cancer. Cancer Metastasis Rev 35: 75-91, 2016.

Received January 30, 2018

Revised February 20, 2018

Accepted February 21, 2018 